\title{
Synthesis and characterization of 3,6-O,O'- dimyristoyl chitosan micelles for oral delivery of paclitaxel
}

\author{
Daniella S. Silva ${ }^{\mathrm{a}}$, Andreia Almeida ${ }^{\mathrm{b}}$, Fabíola Prezotti ${ }^{\mathrm{c}}$, Beatriz Cury ${ }^{\mathrm{c}}$, \\ Sérgio P. Campana-Filho ${ }^{\mathrm{a}, * *}$, Bruno Sarmento ${ }^{\mathrm{b}, \mathrm{d}, *}$ \\ a Institute of Chemistry of São Carlos, University of São Paulo, Avenida Trabalhador São-Carlense, 400-13560-970, São Carlos, SP, Brazil \\ ${ }^{\mathrm{b}}$ Institute for Research and Innovation in Health (i3S) and Institute of Biomedical Engineering (INEB), University of Porto, Rua Alfredo Allen, 208, 4200-393 \\ Porto, Portugal

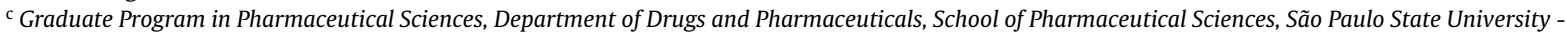 \\ UNESP, Rodovia Araraquara-Jaú, Km 1, 14801-902, Araraquara, SP, Brazil \\ ${ }^{d}$ CESPU, Instituto de Investigação e Formação Avançada em Ciências e Tecnologias da Saúde, Instituto Universitário de Ciências da Saúde, Gandra, Portugal
}

\section{A R T I C L E I N F O}

\section{Article history:}

Received 1 November 2016

Received in revised form 16 January 2017

Accepted 17 January 2017

Available online 18 January 2017

\section{Keywords:}

Chitosan

Amphiphilic

Polymeric micelles

Paclitaxel

Drug delivery

\begin{abstract}
A B S T R A C T
The aim of the present study was to investigate the potential application of 3,6-O,O'- dimyristoyl chitosan DMCh, an amphiphilic derivative of chitosan, for improving the oral bioavailability of paclitaxel (PTX), a water insoluble anticancer drug. The $O$-acylation of chitosan with myristoyl chloride was carried out by employing high $(\approx 13.3)$ or low $(2.0)$ molar excess of chitosan to result in samples DMCh07 and DMCh12, respectively. The successful $O$-acylation of chitosan was confirmed by FTIR and ${ }^{1} \mathrm{H}$ NMR spectroscopy, the latter allowing also the determination of average degree of substitution (DS). The critical aggregation concentration (CAC) of samples DMCh07 (DS $\approx 6.8 \%$ ) and DMCh12 (DS $\approx 12.0 \%$ ) were $8.9 \times 10^{-3} \mathrm{mg} / \mathrm{mL}$ and $13.2 \times 10^{3} \mathrm{mg} / \mathrm{mL}$, respectively. It was observed by TEM that the DMCh micelles showed spherical shape while DLS measurements allowed the determination of their average size $(287 \mathrm{~nm}-490 \mathrm{~nm})$ and zeta potential $(+32 \mathrm{mV}$ to $+44 \mathrm{mV})$. Such DMCh micelles were able to encapsulate paclitaxel with high drug encapsulation efficiency (EE), as confirmed by HPLC analyses. Studies on the cytotoxicity of DMCh07 micelles toward Caco-2 and HT29-MTX cells showed that, regardless the PTX loaded, DMCh07 micelles slightly decreased cellular viability at low micelles concentration $(\leq 1 \mu \mathrm{g} / \mathrm{mL}$ ) while at high concentration $(>10 \mu \mathrm{g} / \mathrm{mL}$ ) PTX-loaded DMCh07 micelles were less toxic toward Caco-2 cells when compared to free PTX. The PTX permeation across Caco-2 monoculture and Caco-2/HT29-MTX co-culture model confirmed the potential of DMCh micelles in improving the intestinal absorption of PTX. These results suggest that DMCh micelles may be a promising carrier to encapsulate PTX aiming cancer therapy.
\end{abstract}

(c) 2017 Elsevier B.V. All rights reserved.

\section{Introduction}

Most of the drugs currently used in clinic for chemotherapy are administered intravenously. However, these agents do not act specifically in malignant cells, affecting healthy cell metabolism as well, causing toxicity and worsening the patient's quality of life [1]. Thus, oral administration of drugs such as PTX has become an attractive strategy for cancer treatments, due to its ease of administration, safety and patient acceptability [2,3]. Naturally, patients have expressed the preference for oral drugs, which brings

\footnotetext{
* Corresponding author at: University of Porto, Institute for Research and Innovation in Health (i3S) and Institute of Biomedical Engineering (INEB), Rua Alfredo Allen, 208, 4200-393, Porto, Portugal.

** Corresponding author.

E-mail address: brunocsarmento@hotmail.com (B. Sarmento).
}

the possibility of home administration with absence of injections [4]. Nonetheless, oral administration of anticancer drugs remains a challenge. Additionally, many chemotherapeutic agents have low water-solubility, limiting their bioavailability and therapeutic effects [5,6]. Indeed, the high hydrophobicity of most anticancer drugs makes difficult their formulation and administration, requiring the use of solubilizing agents that can lead, themselves, to undesirable side effects [7].

Nowadays, paclitaxel (PTX) is one of the most widely used anticancer drugs, and it has been used in clinical treatments against various types of solid tumor malignances due to its antineoplastic activity [8]. The mechanism of action of PTX occurs by disrupting the dynamic equilibrium of the microtubules system, which blocks the cell cycle at the $\mathrm{G} 2$ and $\mathrm{M}$ phases, inhibiting the process of cell replication [9-11]. However, one of the most important restraints to its application is its poor water-solubility $(1 \mu \mathrm{g} / \mathrm{mL})$. 
Despite reports of serious side effects, such as hypersensitivity, neurotoxicity and nephrotoxicity, the solubilizing agent Cremophor EL, mixed with dehydrated ethanol (50:50v/v), has been widely used in the PTX formulation $[9,10]$. Bearing this in mind, new delivery systems have been studied in order to avoid the use of solubilizing agents in the formulation of water insoluble drugs, such as PTX.

Polymer-based micelles have been proposed as drug delivery systems, and as a promising alternative to overcome the limitations related to the solubility issues of PTX [12-14]. The design of polymer-based nanocomposites aiming the targeted antineoplastic delivery presents distinctive importance. These systems gather the possibility of controlling and targeting the drug release with the inherent advantages of the nano-sized particles as protection of the encapsulated drug against degradation and possibility of cellular internalization and retention at specific sites, such as solid tumors. Such features are promising for both the improvement of the therapeutic efficacy and the reduction of the undesired side effects [8].

Polymer-based micelles can originate thermodynamically stable systems at the nanoscale size range $[15,16]$, and these polymer-based nanocomposites represent effective systems to target antineoplastic agents to tumor sites [1]. Micelles based on amphiphilic polymers are seen as promising drug delivery systems due to their capacity to improve the solubility of poorly watersoluble drugs $[14,17,18]$. The hydrophobic core of the micelles promotes the solubilization of water-insoluble active agents, protecting them from degradation [19], while the hydrophilic shell prevents the recognition by the immune system, prolonging the drug circulation [20]. Also, renal excretion may be lowered due to the high molecular weight presented by the micelles [21].

Chitosan has been considered a promising agent for potential applications in biomedical and pharmaceutical field, since it is a cationic biopolymer that exhibits interesting biological activities such as biocompatibility, biodegradability, mucoadhesiveness, antimicrobial and antioxidant properties, and it is likely to be chemically modified, allowing functionalization of surfaces of the carrier of drugs [19,22,23]. Chitosan is a polysaccharide consisting of 2-acetamido-2-deoxy-D-glucopyranose (GlcNAc) and 2-amino-2deoxy-D-glucopyranose $(\mathrm{GlcN})$ units linked by $\beta(1 \rightarrow 4)$ glycosidic bonds with a predominance $(>60 \%)$ of GlcN units [24-26]. The presence of the amino and hydroxyl groups in the structure of chitosan units offers many possibilities for chemical modification, which generally aim to improve the properties of the parent chitosan and/or to introduce new interesting properties [27].

In this study, an amphiphilic chitosan derivative, namely 3,6-O,O'- dimyristoyl chitosan (DMCh), was prepared and its ability to form self-assembled micelles was explored aiming the development of micellar systems to encapsulate PTX. The main physical-chemical characteristics of the resulting micelles, including average size, zeta potential, drug loading efficiency and critical aggregation concentration (CAC), were determined. The in vitro toxicity of the DMCh/PTX micelles was evaluated using Caco-2 (clone C2BBe1) and HT29-MTX cell lines, as well as the permeability assay using Caco-2 monoculture model and Caco-2/HT29-MTX coculture model, and to evaluate the in vitro properties of the micelles developed to promote oral absorption of the drug.

\section{Experimental}

\subsection{Synthesis of 3,6-0,0'-dimyristoyl chitosan DMCh}

Briefly, chitosan was suspended in $\mathrm{MeSO}_{3} \mathrm{H}$ and kept for $1 \mathrm{~h}$ under mechanical stirring to allow its complete dissolution, resulting in $\mathrm{Cp}=4 \%(\mathrm{w} / \mathrm{v})$. Then, a predetermined amount of myristoyl chloride was added to the polymer solution to result in high $(\approx 13.3)$ or low $(2.0)$ molar excess of chitosan. The mixture was kept under mechanical stirring for $1 \mathrm{~h}$ at $25^{\circ} \mathrm{C}$ and then it was poured into $500 \mathrm{~mL}$ of ice/water, the suspension was centrifuged, and $\mathrm{MeSO}_{3} \mathrm{H}$ was removed. The product was washed with distilled water, followed by neutralization with $5 \%(\mathrm{w} / \mathrm{v})$ aqueous sodium bicarbonate. The solid was filtered, extensively rinsed with distilled water, followed by extraction with chloroform in Soxhlet overnight. Finally, the product was dried in a vacuum oven at room temperature $\left(25^{\circ} \mathrm{C}\right)$. The chitosan derivative produced by using the higher excess of chitosan was named as sample DMCh07 while sample DMCHh12 resulted when the lower excess of chitosan was used.

\subsection{Characterization of DMCh}

\subsubsection{Fourier transform infrared spectroscopy (FTIR)}

Infrared spectra were recorded on an IRAffinity-1 Shimadzu spectrometer. Samples and $\mathrm{KBr}$, previously dried in vacuum oven at $60{ }^{\circ} \mathrm{C}$ for $8 \mathrm{~h}$, were mixed at a mass ratio 1:100 (sample: $\mathrm{KBr}$ ), and then compressed into pellet form. The IR spectra were acquired in the range of $4000-400 \mathrm{~cm}^{-1}$ and accumulation of 32 scans and resolution of $4 \mathrm{~cm}^{-1}$.

\subsection{2. ${ }^{1} \mathrm{H}$ NMR spectroscopy}

The ${ }^{1} \mathrm{H}$ NMR spectra were acquired at $80^{\circ} \mathrm{C}$ by using a Bruker AVANCE III spectrometer $(v=400 \mathrm{MHz})$. For these analyses, DMCh was dissolved in $1 \% \mathrm{HCl} / \mathrm{D}_{2} \mathrm{O}(1 / 1 \mathrm{v} / \mathrm{v})$ to result in $\mathrm{Cp}=10 \mathrm{mg} / \mathrm{mL}$. The average degree of acetylation (DA) of chitosan was determined from the ratio of the signal areas assigned to the methyl hydrogens of the acetamido groups of GlcNAc units and the hydrogens bound to carbons 2-6 of the glucopyranose ring [28]. The average degree of substitution(DS) of samples DMCh07 and DMCh12 at the hydroxyl $(0-3$ and $O-6)$ and amino (C2) groups were determined from their ${ }^{1}$ H NMR spectra. Thus, the value of DS was calculated from the ratio of the values of the integrals of the signals at $\approx 0.8 \mathrm{ppm}$ (methyl hydrogens of myristoyl substituent) and at $\approx 3.0-4.5 \mathrm{ppm}$, which are due to the hydrogens bound to carbons 2-6 of the glucopyranose ring.

\subsubsection{WeBTability}

The wettability of DMCh samples was evaluated by contact angle measurements using the sessile drop method [30]. The analyses were carried out in a contact angle apparatus (OCA15, Dataphysics Instruments Co. Ltd, Germany) at room temperature $\left(25^{\circ} \mathrm{C}\right)$. The DMCh sample in pellet form was placed on the holder and a droplet of ultrafiltered water $(4 \mu \mathrm{L})$ was placed on the surface using a microsyringe. A high performance CCD camera recorded the initial contact angle as soon as the droplet was on the sample surface $[3,4]$. The values of contact angle did not vary as a function of time.

\subsubsection{Critical aggregation concentration (CAC)}

The CAC of DMCh samples in $0.1 \mathrm{M}$ acetic acid was determined by using the conductivity method. Thus, the conductivity of polymer solutions as a function of polymer concentration $\left(1 \times 10^{-6} \mathrm{mg} / \mathrm{mL} \leq \mathrm{Cp} \leq 1 \mathrm{mg} / \mathrm{mL}\right)$ at $25^{\circ} \mathrm{C}$ under continuous stirring was measured by using a Consort C863 condutivimeter (Spain) [32].

\subsection{Preparation and characterization of PTX-loaded DMCh micelles}

PTX-loaded DMCh micelles were prepared by the solvent evaporation method. Briefly, DMCh was dissolved in $0.1 \mathrm{M}$ acetic acid to result in $\mathrm{Cp}=1 \mathrm{mg} / \mathrm{mL}$. PTX was dissolved in ethanol $70 \%$ and this solution $(1 \mathrm{mg} / \mathrm{mL})$ was added to the DMCh solution to result in mass ratio polymer:drug of $0.1-2.0 \%$. This solution was stirred 
at $300 \mathrm{rpm}$, for $4 \mathrm{~h}$ at $25^{\circ} \mathrm{C}$ to allow the complete evaporation of ethanol. Next, the solution was sonicated for 5 min using a probetype sonicator (Vibra-cell, Sonics Material INC. Danbury, USA) in iced bath. To remove non-encapsulated drug, the solution was centrifuged through Amicon ${ }^{\circledR}$ Ultra-15 filter with $100 \mathrm{kDa}$ pores, at $5000 \mathrm{rpm}$ for $10 \mathrm{~min}$.

The non-encapsulated drug was collected and the drug concentration was determined by HPLC-UV method. The HPLC Merck-Hitachi 7000 with column LiChrospher ${ }^{\circledR} 100$ RP-18 $5 \mu \mathrm{m}$ Merck Millipore was used for the separation. The mobile phase was composed by methanol/water $(65: 35 \mathrm{v} / \mathrm{v})$, the flow rate and column temperature were set at $1 \mathrm{~mL} / \mathrm{min}$ and $25^{\circ} \mathrm{C}$, respectively. The concentration of PTX (retention time $\approx 7.8 \mathrm{~min}$ ) was monitored by measuring the absorbance at $\lambda=227 \mathrm{~nm}$. The experiments were performed in triplicate at $25^{\circ} \mathrm{C}$, and the total area of the peak was used to quantify the amount of free PTX, allowing the determination of encapsulation efficiency (EE) and loading capacity (LC).

$\mathrm{EE} \%=\frac{\text { total amount of PTX }- \text { free PTX precipitate }}{\text { total amount of PTX }} \times 100$

$\mathrm{LC} \%=\frac{\text { total amount of PTX }- \text { free PTX precipitate }}{\text { total weight of micelles }} \times 100$

\subsubsection{Micelles size and morphology}

The size and dispersity index were measured by dynamic light scattering (DLS) using a detection angle of $173^{\circ}$ (ZetaSizer Nano ZS, Malvern, UK). At least three replicates of each formulation were produced and analysed. Transmission electron microscopy (TEM) measurements were performed using a JEOL JEM 1400 TEM microscope (Tokyo, Japan) and the images were digitally recorded using a Gatan SC 1100 ORIUS CCD camera (Warrendale, PA, USA). PTX-loaded micelle aqueous solution was placed on a film-coated copper grid.

\subsection{In vitro studies}

\subsubsection{Cell culturing reagents}

Caco-2 cells (clone C2BBe1) were obtained from American Type Culture Collection (ATCC, USA), and HT29-MTX cell line was kindly provided by Dr. T. Lesuffleur (INSERMU178, Villejuif, France). Dulbecco's Modified Eagle Medium (DMEM, Lonza), supplemented with $10 \%(\mathrm{v} / \mathrm{v})$ fetal bovine serum (FBS) (Merck Millipore), 1\% (v/v) penicillin (100 UI/mL, Merck Millipore) and streptomycin $(100 \mu \mathrm{g} / \mathrm{mL}$, Merck Millipore) and $1 \%$ $(\mathrm{v} / \mathrm{v})$ nonessential amino acids (NEAA, Merck Millipore). 3-(4,5dimethylthiazol-2-yl)-2,5- diphenyltetrazolium bromide (MTT) and dimethyl sulfoxide (DMSO) of the Sigma Aldrich, Triton X-100 $1 \%$ (Spi-Chem) [33].

\subsubsection{Cytotoxicity assay}

The toxicity of PTX-loaded DMCh micelles and free drug was assessed in Caco-2 and HT29-MTX cell lines, using the MTT reagent. The cells were cultivated in culture flasks with medium consisting of DMEM supplemented with $10 \%(\mathrm{v} / \mathrm{v}) \mathrm{FBS}, 1 \%(\mathrm{v} / \mathrm{v})$ L-glutamine, $1 \%(\mathrm{v} / \mathrm{v}) \mathrm{NEAA}$, and $1 \%(\mathrm{v} / \mathrm{v})$ antibiotic-antimitotic mixture (concentration of $100 \mathrm{U} / \mathrm{mL}$ Penicillin and $100 \mathrm{U} / \mathrm{mL}$ Streptomycin). Cells were seeded $(200 \mu \mathrm{L})$ into wells of 96 -well plates with $1 \times 10^{4}$ cells/well for HT29-MTX cell line and $2 \times 10^{4}$ cells/well for Caco2 and then they were incubated overnight at standard conditions to reach exponential growth prior to the assay test. On the following day, the medium was removed and cells were washed twice with $200 \mu \mathrm{L}$ of phosphate buffered saline (PBS). After, the cells were treated with free PTX and PTX-loaded micelles in the concentration range of $0.001-1000 \mu \mathrm{g} / \mathrm{mL}$. The positive control was DMEM and negative control was $1 \%(\mathrm{w} / \mathrm{v})$ Triton X-100. The cultured cells were incubated for $24 \mathrm{~h}$ in the presence of different concentrations of samples. Then, samples were removed and $200 \mu \mathrm{L}$ of the MTT reagent $(0.5 \mathrm{mg} / \mathrm{mL})$ was added followed by an incubation period of $4 \mathrm{~h}$. After, the MTT was removed and $200 \mu \mathrm{L}$ of DMSO were added to each well to dissolve the formazan crystals. The plates were vigorously shaken for $10 \mathrm{~min}$ inside the microplate reader before the relative color intensity was measured at $570 \mathrm{~nm}$ and taking the absorbance at $630 \mathrm{~nm}$ as a reference, by using a microplate reader (Synergy 2, Biotek Instruments Ltda, USA).

\subsubsection{Permeability assay}

For this experiment, monoculture model of Caco-2 cells and coculture model Caco-2:HT29-MTX at the proportion of 90:10 were seeded in the Transwell ${ }^{\mathrm{TM}}$ plates Falcon (transparent PET membrane with $3 \mu \mathrm{m}$ pore diameter, $4.67 \mathrm{~cm}^{2}$ ), as previously reported [34]. The intestinal cells were seeded on the apical compartment of Transwell ${ }^{\mathrm{TM}}$ inserts to a final density of $4.5 \times 10^{5}$ cells $/ \mathrm{cm}^{2}$ by insert. Cells were grown until forming a monolayer for 21 days with the medium replacement every other day.

Before permeability experiments, DMEM was removed from both chambers and the Transwell ${ }^{\mathrm{TM}}$ insert was washed twice with pre-warmed Hank's buffered salt solution (HBSS), then was replaced by new HBSS and allowed to equilibrate for $30 \mathrm{~min}$ at $37^{\circ} \mathrm{C}$. Permeability studies of free PTX and PTX-loaded micelles were run at $37^{\circ} \mathrm{C}$ during $3 \mathrm{~h}$ and, at different time points $(15,30$, $45,60,90,120$ and $180 \mathrm{~min}$ ), $200 \mu \mathrm{L}$ of each sample was taken from the basolateral side of the Transwell ${ }^{\mathrm{TM}}$ insert and the same volume of pre-warmed HBSS was added to replace the withdrawn volume. At the end of the experiment, all volume $(1.5 \mathrm{~mL})$ of the apical compartment was removed for further analysis. All samples were quantified by HPLC analysis, as already described above. The cells monolayers integrity was measured before change medium from twice to three times a week and at the end of the permeability studies, using an EVOM Epithelial Voltohmmeter Instrument with chopstick electrodes (World Precision Instruments, Sarasota, FL, USA) [34]. The permeability results were expressed in cumulative mass $(\mu \mathrm{g})$ and TEER values were normalized by subtracting the resistance value of the empty insert and expressed in percentage.

\subsubsection{Statistical analysis}

All the experiments were performed in triplicate and are represented as mean \pm standard deviation (SD). Statistical analyses of micelles size and morphology were carried out using the Minitab

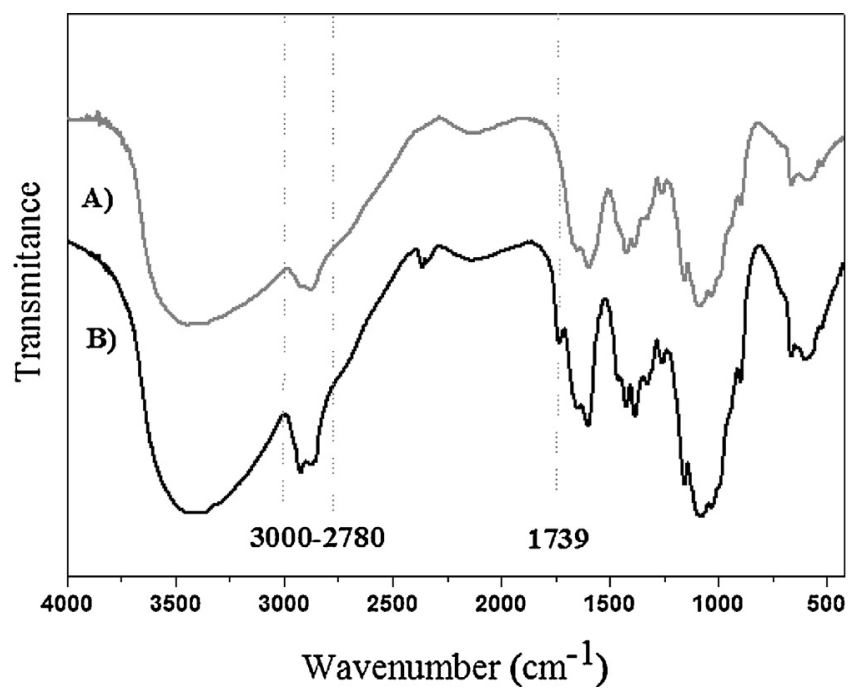

Fig. 1. Infrared spectra of chitosan (A) and sample DMCh07 (B). 

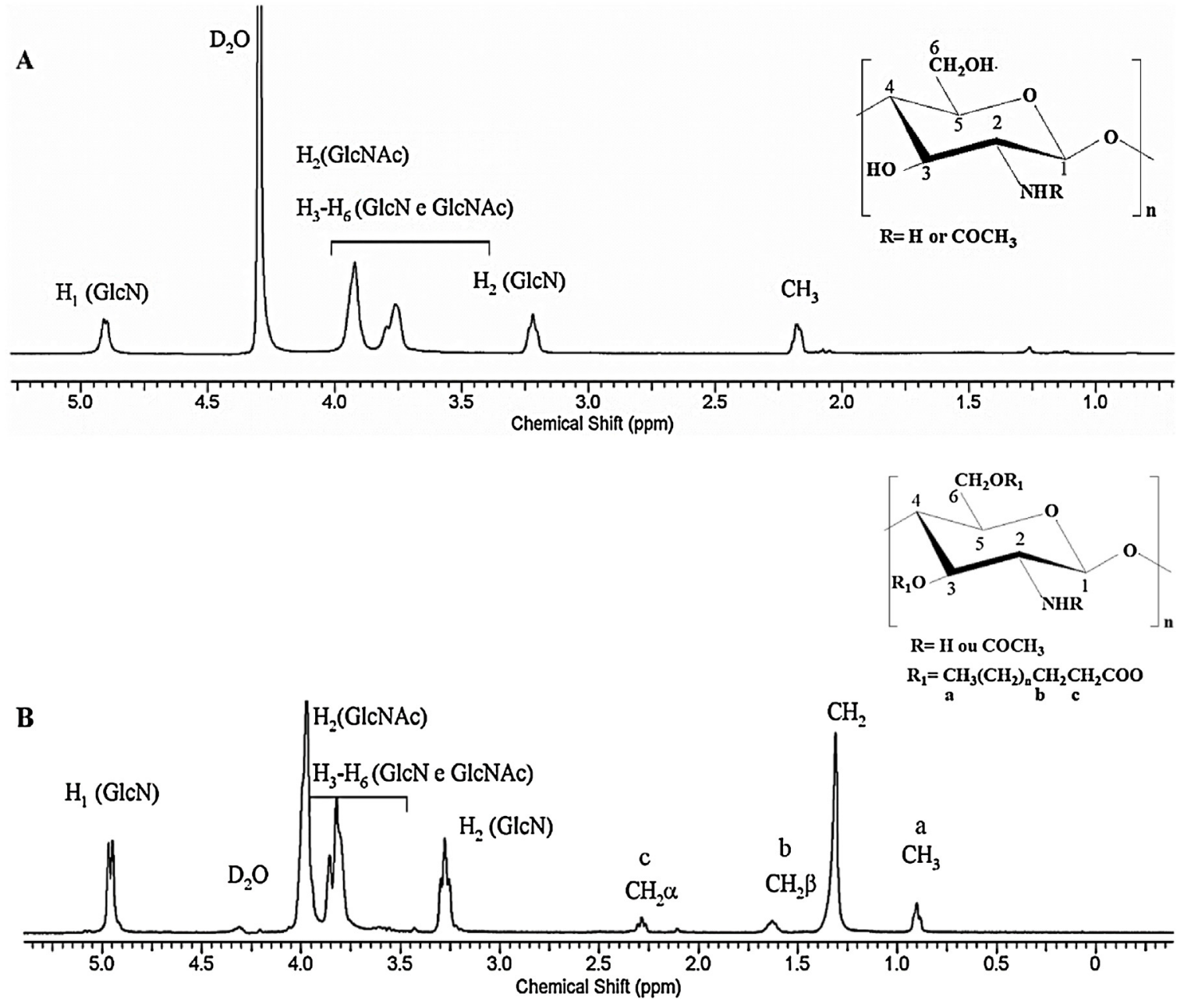

Fig. 2. ${ }^{1} \mathrm{H}$ NMR spectra of (A) chitosan and (B) DMCh07 derivative of chitosan in $\mathrm{DCl} / \mathrm{D}_{2} \mathrm{O} 1 \%(\mathrm{v} / \mathrm{v}), 80^{\circ} \mathrm{C}$.

program. Statistical significance between different treatments was determined using analysis of variance (ANOVA) post hoc Tukey's test a $p$-value $\leq 0,05$ was used to determine significant differences for results of DLS and HPLC. A two-way analysis of variance (ANOVA) with Bonferroni Multiple/Post Hoc Group Comparisons (GraphPadPrism software Inc., USA) was used to analyze the cytotoxicity data. The level of significance was set at probabilities of ${ }^{*} \mathrm{p}<0.05,{ }^{* *} \mathrm{p}<0.01$, and ${ }^{* * *} \mathrm{p}<0.001$.

\section{Results and discussions}

\subsection{Structural characterization of DMCh}

FTIR and ${ }^{1} \mathrm{H}$ NMR spectroscopy were used to characterize the typical functional groups of chitosan and DMCh samples (Fig. 1A). The FTIR spectra of chitosan and DMCh07 (Fig. 1A) showed the same main bands at: i) $1670-1650 \mathrm{~cm}^{-1}$, amide I band, corresponding

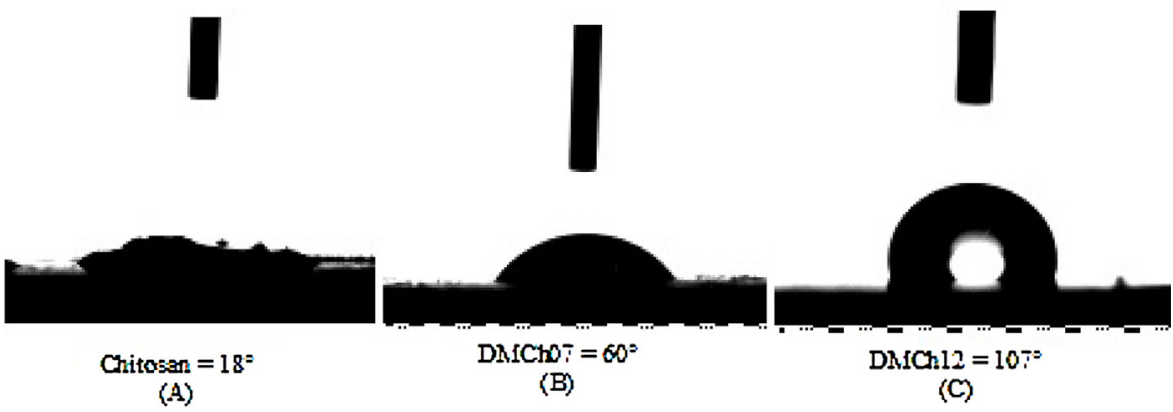

Fig. 3. Water contact angle of samples (A) chitosan, (B) DMCh07 and (C) DMCh12. 
to the axial deformation of $\mathrm{C}=\mathrm{O}$; ii) $1600-1500 \mathrm{~cm}^{-1}$, amide II band, due to angular deformation of $\mathrm{N}-\mathrm{H}$; iii) 1380 and $1370 \mathrm{~cm}^{-1}$, due to axial deformation of methyl group; iv) $1320-1300 \mathrm{~cm}^{-1}$, amide III band, due to axial deformation of CN; v) $1070-1060 \mathrm{~cm}^{-1}$, due to the angular deformation of $\mathrm{C}-\mathrm{O}[19,35,36]$. The spectra of both polymers also show a strong and broad band in the range $3500 \mathrm{~cm}^{-1}-3300 \mathrm{~cm}^{-1}$ corresponding to the axial deformation of $\mathrm{O}-\mathrm{H}$ and $\mathrm{N}-\mathrm{H}$ bonds, and the bands at $3000-2780 \mathrm{~cm}^{-1}$, which are assigned to axial deformation of $\mathrm{C}-\mathrm{H}$.

In addition to the above mentioned bands, it is possible to observe in the FTIR spectrum of sample DMCh07 (Fig. 1B) a weak band centered at $1739 \mathrm{~cm}^{-1}$, which is attributed to axial deformation of carbonyl ester, resulting from the $O$-acylation of chitosan $[35,37]$. The spectra of samples DMCh07 and DMCh12 showed the same characteristic bands and in both cases the intensity of the carbonyl ester band was low, probably due to their low degree of substitution.

The following characteristic signals were observed in the ${ }^{1} \mathrm{H}$ NMR spectrum of the chitosan sample: $2.2 \mathrm{ppm}$ due to methyl hydrogens pertaining to acetamido groups of GlcNAc units; 3.6 $4.0 \mathrm{ppm}$, attributed to the hydrogens $\mathrm{H} 3-\mathrm{H} 6$ of GlcN unit and $\mathrm{H} 2$ of GlcNAc unit; 3.1-3.3 ppm H2 of GlcN units; 4.9 ppm, attributed to the hydrogen bonded to the anomeric carbon 1 (Fig. 2A) [29,38]. Additionally, the average degree of acetylation of chitosan was calculated from its ${ }^{1} \mathrm{H}$ NMR spectrum resulting in $\mathrm{DA}=5 \%$. The ${ }^{1} \mathrm{H}$ NMR spectrum of DMCh07 (Fig. 2B) shows characteristic peaks of myristoyl group at $0.9,1.3,1.7,2.3$ and $3.2 \mathrm{ppm}$, which are due to the hydrogen atoms of $\mathrm{CH}_{3}, \mathrm{CH}_{2}, \mathrm{CH}_{2}(\beta)$ and $\mathrm{CH}_{2}(\alpha)$ moieties. The peaks at 3.0-4.5 ppm refer to the hydrogens of carbons $2-6$ of chitosan [36,39-42]. The average degree of substitution (DS) of samples DMCh07 and DMCh12 were $6.8 \%$ and $12 \%$, respectively, as determined from their ${ }^{1} \mathrm{H}$ NMR spectra.

Owing to the use of a lower molar excess of chitosan to carry out the $O$-acylation reaction, DMCh12 exhibits a higher value of DS as compared to DMCh07. Indeed, as the same chitosan batch was used in both reactions, the number of hydroxyl sites in polymer chains is fixed, and the higher availability of myristoyl chloride to react results in a more acylated chitosan derivative. Additionally, FTIR and RMN spectra showed no evidences of $\mathrm{N}$-acylation which is attributed to the full protonation of amino groups of chitosan due to strong acidity of the reaction medium. In fact, as the acylation of chitosan occurs via nucleofilic attack to the carbonyl of myristoyl chloride and taking into account that methanesulfonic acid is a very strong acid $(\mathrm{pKa} \approx-1.9)$ [43], the full protonation of the primary amino groups pertaining to GlcN units $(\mathrm{pKa} \approx 6.5)$ [44] prevents the occurrence of $\mathrm{N}$-acylation of chitosan. Thus, it is not expected any occurrence of effect, as long as the reaction is carried out in methanesulfonic acid. However, taking into account that in methanesulfonic acid, chitosan chains assume a full extended, rodlike conformation due the high charge density conferred by the full protonation of amino groups pertaining to GlcN units, polymer aggregation is prevented and the molecular weight should not affect the accessibility of the acylating reagent to hydroxyl sites of chitosan.

The water contact angle analysis was performed to investigate the wetting behavior of chitosan, DMCh07 (DS = 6.8\%) and DMCh12 (DS $=12 \%$ ), and thus, evaluate the hydrophobic effect caused by the presence of myristoyl groups in the chains of DMCh as compared to unmodified chitosan. It is possible to observe in Fig. 3 that the surface of the chitosan sample exhibited a high hydrophilicity as the contact angle with water droplet was $18^{\circ}$, which is mainly due to interactions between its amino and hydroxyl groups with water molecules [31]. On the other hand, the contact angles of DMCh07 and DMCh12 surfaces with water droplet were $60^{\circ}$ and $107^{\circ}$, respectively, revealing the high hydrophobicity of such samples as

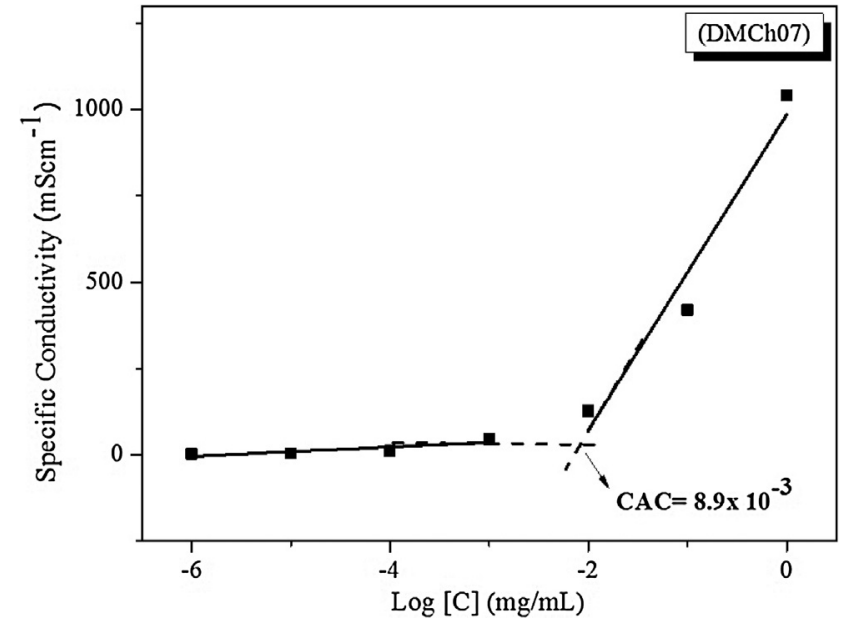

Fig. 4. Plot of specific conductivity as a function of logarithm concentration of DMCh07 of $1 \mathrm{mg} / \mathrm{mL}$ to $1 \times 10^{-6} \mathrm{mg} / \mathrm{mL}$.

compared to unmodified chitosan and confirming that the presence of myristoyl groups is responsible for such a behavior. Indeed, these data also reveals that the higher the content of myristoyl substituents, the higher the contact angle and the hydrophobicity of the sample surface.

The conductivity measurements of aqueous solutions of the DMCh07 and DMCh12 samples were carried out to evaluate the occurrence of macromolecular aggregation. This technique was chosen because it is simple, fast, and low cost and its results are reproducible and comparable to those acquired by using other techniques, such as dynamic light scattering, surface tension and spectrofluorimetry. Thus, the CAC values of the DMCh07 and DMCh12 samples were determined from the plots of specific conductivity versus $\log (\mathrm{Cp})$, where $\mathrm{Cp}$ is the polymer concentration, by taking the intersection between the straight lines corresponding to low $\left(\mathrm{Cp} \leq 10^{-3} \mathrm{mg} / \mathrm{mL}\right)$ and high $\left(\mathrm{Cp} \geq 10^{-2} \mathrm{mg} / \mathrm{mL}\right)$ polymer concentration. The specific conductivity versus $\log (\mathrm{Cp})$ curve corresponding to sample DMCh07 (Fig. 4) shows two linear parts. In the first part before $\mathrm{CAC}$, the increase in solution conductivity with increasing DMCh07 concentration reflects the presence of more positively charged species, due to ammonium groups distributed along the polymer chains, as the polymer concentration is increased. In the second part of the curve specific conductivity versus $\log (\mathrm{Cp})$ (after $\mathrm{CAC}$ ), the medium is saturated with micelles and the addition of more DMCh07 contributes to increase the solution conductivity as the already formed micelles are not able to aggregate new polymer chains. The micellar systems are formed when the concentration of amphiphilic compound is higher than a critical value, known as critical aggregation concentration, and from then on it is possible to evaluate the stability of micelles [45]. The values of CAC of samples DMCh07 and DMCh12 were $8.9 \times 10^{-3} \mathrm{mg} / \mathrm{mL}$ and $13.2 \times 10^{-3} \mathrm{mg} / \mathrm{mL}$, respectively, which are lower than those of low molecular weight surfactants, such as sodium dodecyl sulphate $(\mathrm{CAC}=2.3 \mathrm{mg} / \mathrm{mL})[46]$.

\subsection{Size and morphology}

The empty and PTX-loaded micelles were characterized according to the average size, dispersity and zeta potential and these results showed that the differences between means that share a letter are not statistically significant (Table 1 ). The average size of the DMCh micelles ranged from $287 \mathrm{~nm}$ to $490 \mathrm{~nm}$ (Table 1 ), the empty micelles of DMCh12 being bigger as compared to DMCh07 micelles, probably due to the higher DS of DMCh12 as in this case more hydrophobic groups are hosted inside the micelles. The aver- 
Table 1

Characterization of DMCh empty and DMChs-PTX loading.

\begin{tabular}{|c|c|c|c|c|c|c|c|c|}
\hline \multirow[t]{3}{*}{ Drug(\%) } & \multicolumn{8}{|l|}{ Micelles - PTX } \\
\hline & \multicolumn{4}{|l|}{ Sample DMCh07 } & \multicolumn{4}{|c|}{ Sample DMCh12 } \\
\hline & Size $(\mathrm{nm})^{1 \#}$ & $\mathrm{PDI}^{2 \#}$ & Zeta $(\mathrm{mV})^{3}$ & $\overline{\mathrm{EE}(\%)^{4}}$ & Size $(\mathrm{nm})^{1 \#}$ & $\mathrm{PDI}^{2 \#}$ & Zeta $(\mathrm{mV})^{3}$ & $\mathrm{EE}(\%)^{4}$ \\
\hline 2.00 & $481.6 \pm 91.4^{\mathrm{a}}$ & $0.52 \pm 0.11^{\mathrm{a}, \mathrm{b}, \mathrm{c}}$ & $35.23 \pm 5.31^{\mathrm{a}}$ & $100^{* a}$ & $373.2 \pm 24.6^{c}$ & $0.21 \pm 0.02^{c}$ & $44.00 \pm 0.78^{a}$ & $99.57 \pm 13.36^{\mathrm{a}}$ \\
\hline 1.00 & $332.2 \pm 41.8^{c}$ & $0.47 \pm 0.05^{\mathrm{a}, \mathrm{b}}$ & $36.45 \pm 2.86^{b}$ & $100^{* a}$ & $492.5 \pm 78.1^{b}$ & $0.34 \pm 0.01^{\mathrm{b}, \mathrm{c}}$ & $43.50 \pm 1.11^{\mathrm{a}}$ & $95.59 \pm 7.86^{a}$ \\
\hline 0.50 & $346.9 \pm 19.8^{\mathrm{c}, \mathrm{d}}$ & $0.44 \pm 0.08^{\mathrm{a}, \mathrm{b}}$ & $36.32 \pm 0.90^{\mathrm{b}}$ & $100^{* a}$ & $342.3 \pm 81.2^{\mathrm{d}, \mathrm{e}}$ & $0.52 \pm 0.03^{a}$ & $35.80 \pm 3.04^{b}$ & $100.00 \pm 0.97^{a}$ \\
\hline 0.10 & $289.9 \pm 7.3^{\mathrm{d}, \mathrm{e}}$ & $0.45 \pm 0.09^{a, b}$ & $36.07 \pm 2.80^{\mathrm{b}}$ & $100^{* a}$ & $287.0 \pm 36.1^{\mathrm{d}, \mathrm{e}}$ & $0.50 \pm 0.11^{\mathrm{a}, \mathrm{b}}$ & $35.90 \pm 3.00^{\mathrm{b}}$ & $99.99 \pm 1.18^{\mathrm{a}}$ \\
\hline 0.00 & $356.0 \pm 20.5^{c, d, e}$ & $0.52 \pm 0.03^{\mathrm{a}, \mathrm{b}}$ & $32.11 \pm 4.43^{\mathrm{b}}$ & - & $462.0 \pm 9.9^{b}$ & $0.46 \pm 0.04^{\mathrm{a}, \mathrm{b}}$ & $34.20 \pm 2.20^{\mathrm{b}}$ & - \\
\hline
\end{tabular}

Size ${ }^{1}$, dispersity ${ }^{2}$ and zeta potential ${ }^{3}$ were determined by dynamic light scattering. Percentage of PTX encapsulation efficiency ${ }^{4}$. ${ }^{*}$ Beyond the detection limit of the HPLC. Values were reported as mean $\pm \operatorname{SD}(n=\mathbf{3})$. $\left({ }^{\mathrm{a}, \mathrm{b}}\right.$ and ${ }^{\mathrm{c}}$ ) denotes a significant difference $(p$-value $\leq 0.05)$. ${ }^{\#}$ All formulations presented monomodal profile.

age size of micelles charged with low PTX content ( $0.1 \%$ and $0.5 \%)$ were similar, regardless of being composed by DMCh07 or DMCh12, but increasing the PTX loading (up to $2 \%$ ) resulted in volume contraction in the case of DMCh12 micelles while DMCh07 micelles exhibited a volume expansion as compared to the corresponding empty micelles. Such a behavior can also be attributed to the different DS values of DMCh07 (=6.8\%) and DMCh12 (=12.0\%) as in the former case the low content of hydrophobic moieties inside de micelles disfavors the interactions polymer/PTX, resulting in volume expansion, while such interactions are favored in the latter case due to the higher content of myristoyl substituents in DMCh12 chains, and a volume contraction is observed consequently.

The measurement of the zeta potential of the surface of particles and micelles suspended in a given medium allows one to evaluate the stability of such suspensions as the repulsive electrostatic forces acting among equally charged species contribute to stabilize these systems [45]. According to the data shown in Table 1, empty and PTX-loaded micelles exhibited high positive zeta potential values $(>30 \mathrm{mV})$, regardless of being composed by DMCh07 or DMCh12, which is attributed to the high content of ammonium groups, pertaining to segments of the main polymer chains, at the micelles surfaces. The zeta potential values of empty and PTX-loaded DMCh07 micelles were slightly different while an increase of zeta potential with increasing PTX load, mainly for high PTX loadings (1.0\% and $2.0 \%$ ), was observed in the case of DMCh12 micelles (Table 1). Such behavior can be attributed to the fact that the formation of micelles occurs by association of hydrophobic moieties of polymer chains to constitute the micelles core while the hydrophilic moieties and charged polymer segments are exposed to the aqueous medium, $i$. $e$. these latter are predominantly located at the micelles surface. However, DMCh07 and DMCh12 are not block copolymers as the $O$-alcylation of chitosan was carried out in solution of methanesulfonic acid, strongly favoring the random distribution of substituents along polymer chains, the structural characterization confirming the predominant occurrence of $O, O^{\prime}$-disubstitution. Therefore, the surfaces of DMCh micelles probably contain hydrophobic moieties as well as a certain fraction of hydrophilic groups can be located at the micelles core. Thus, probably due to its low content of hydrophobic substituents, the hydrophilic segments of DMCh07 chains are predominantly exposed at the micelles surface, regardless of the load PTX, and the zeta potential ranges in a narrow interval. On the contrary, probably because of the higher content of myristoyl substituents in DMCh12 chains, hydrophobic segments are also located at the DMCh12 micelles surfaces in the cases of empty and at low PTX loaded micelles, and the zeta potential values of DMCh07 and DMCh12 micelles were quite similar. However, at higher loaded PTX (1\% and $2 \%$ ) the zeta potential of DMCh12 micelles was significantly higher as compared to empty micelles and to DMCh07 micelles, revealing that more charged segments have been exposed at the micelles surface. Indeed, such a higher exposure of hydrophilic polymer segments at the DMCh07 micelles surface at high loaded PTX was accompanied by a significant decrease of the micelles average diameter as compared to empty micelles (Table 1), which has been attributed to the more favorable interactions polymer/PTX the higher the content of myristoyl substituents. TEM studies demonstrated that DMCh micelles were spherical in shape and well dispersed without aggregation (Fig. 5).

\subsection{Drug loading DMCh-PTX micelles}

In the present study, the potential anticancer drug, PTX, was used as a drug model to be encapsulated into DMCh07 and DMCh12 micelles, the encapsulation efficiency (EE) being evaluated by HPLC. The EE values (Table 1) were not significantly different at the studied drug loaded $(0.5 \%$ to $2 \%)$ as both micelles systems exhibited high loading capacity of PTX $(\approx 100 \%)$, revealing none influence of the DS on it. Additionally, both micelles systems were stable as the formation of larger particles and/or particles precipitation were not observed.
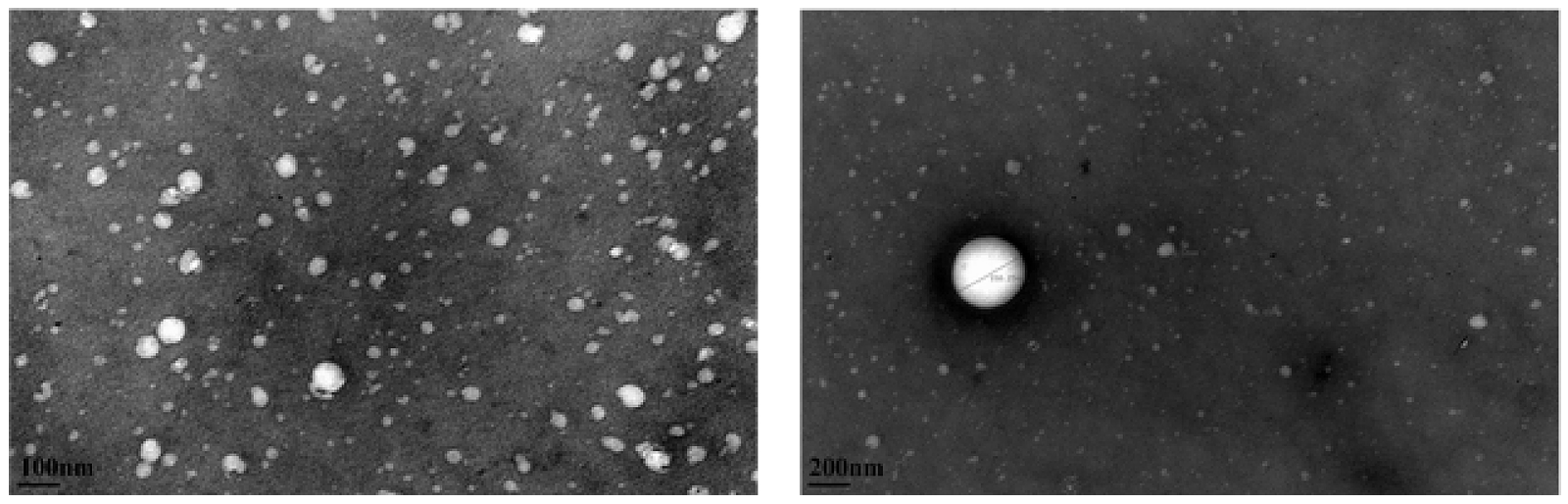

Fig. 5. TEM images showing the shape and size of DMCh07 with ratio 100/2 polymer/drug, with a scale corresponding to $100 \mathrm{~nm}$ and $200 \mathrm{~nm}$, respectively. 

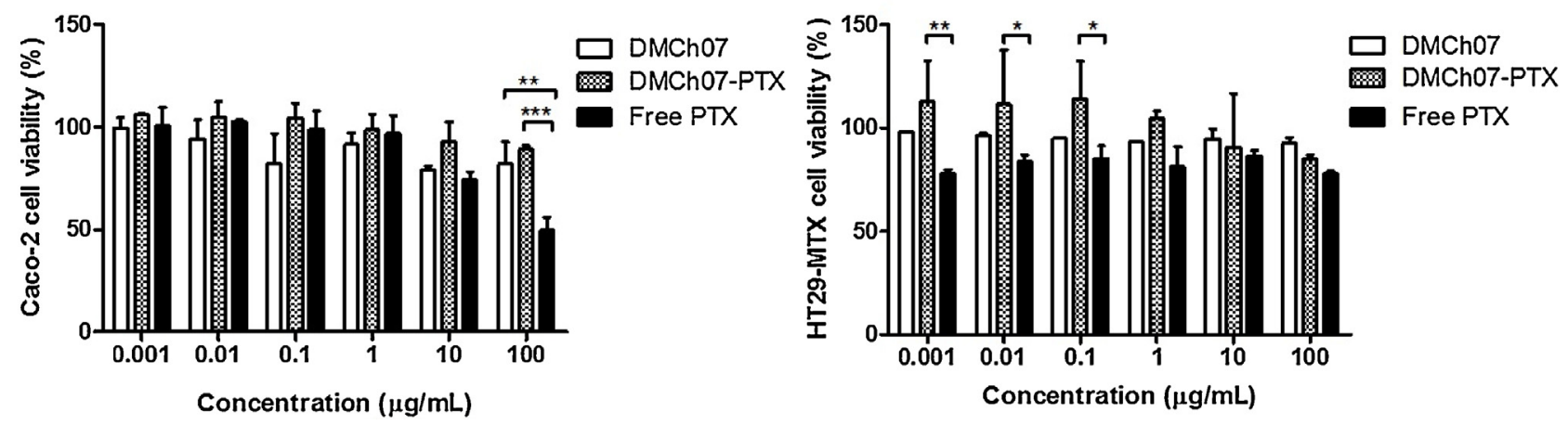

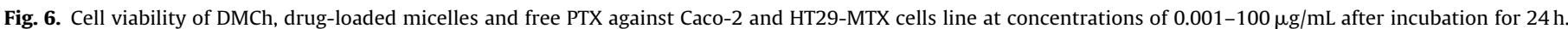
Values were reported as mean $\pm \operatorname{SD} \boldsymbol{n}=\mathbf{3}\left({ }^{* *}\right)$ and $\left({ }^{* * *}\right)$ denotes a significant difference $(\mathrm{p}<0.01$ and $\mathrm{p}<0.001$, respectively).

\subsection{In vitro cytotoxicity assay of DMCh-PTX micelles}

According to results presented above, the derivative chosen to develop the biological assays was sample DMCh07, as it presents ratio polymer/drug of $100 / 2(\mathrm{w} / \mathrm{w})$. Indeed, the main aim was to encapsulate and solubilize the hydrophobic drug, but the choice was also based on the low degree of substitution of DMCh07, to avoid the exposure of hydrophobic segments at the micelles surface.

To evaluate the intestinal safety and biocompatibility of the DMCh07 polymer, empty DMCh07 and PTX-loaded micelles were used to carry out the in vitro assays with Caco-2 and HT29-MTX intestinal cells. Samples were incubated during $24 \mathrm{~h}$ and cell viability was assessed by MTT assay. The relative cell viability in the different models cells treated with several concentrations of samples DMCh07, DMCh07-PTX (ratio 100:2 w/w) and PTX is shown in Fig. 6. It was observed that at higher sample concentration $(100 \mu \mathrm{g} / \mathrm{mL})$, Caco-2 model intestinal cells presented significant higher viability in the presence of PTX-loaded DMCh07 micelles as compared to those incubated in the presence of free PTX. Clearly the results showed that the DMCh07 and PTX-loaded DMCh07 micelles exhibit lower cytotoxicity as compared to free PTX, which was consistent with other reports [1,2]. Accordingly, one may conclude that encapsulating PTX into DMCh07 micelles reduced its cytotoxicity.

The HT29-MTX cells also presented high viability in the presence of DMCh07 and PTX-loaded DMCh07 micelles, the latter exhibiting lower cytotoxicity as compared to free PTX (Fig. 6), proofing that the encapsulation is advantageous. Indeed, these results can be taken as proof of concept, in the sense the encapsulation of PTX into DMCh07 micelles is safe for oral administration. However, it is important to highlight that this assay was not performed to evaluate the antitumor efficacy of PTX, but to assess the safety of the materials in the presence of intestinal cells. Thus, it was concluded that for both cell lines, i. e. Caco-2 and HT29-MTX cells, DMCh-based micellar system presented very low cytotoxicity, being safe to be used in the release of PTX.

\subsection{In vitro permeability assay of PTX-loaded micelles}

As mentioned above, oral administration of PTX is the desirable choice. Also, nanotechnology against cancer has been widely focused on polymer micelles to improve the oral absorption of PTX $[47,48]$. The objective of this experiment was to assess the effect of the amphiphilic chitosan derivative, 3,6-0,0<span class= ability in vitro. Besides the standard model to study the in vitro intestinal permeability of drugs, that consists of a Caco-2 monoculture, a co-culture model consisting of Caco-2/HT29-MTX cell lines was also used, in order to evaluate the role of mucus in the permeability of PTX from the micelles [34].

The cumulative amount of PTX permeated was plotted as a function of time and is shown in Fig. 7. For both models, in the first 90 min the cumulative amount of PTX that permeated through the cell monolayers had a similar profile. After $90 \mathrm{~min}$, the Caco-2 model showed an increased on drug permeability, reaching a PTX cumulative mass of $0.50 \mu \mathrm{g}$ and at the end of the test, $1.0 \mu \mathrm{g}$ of PTX was permeated across the monolayer. For the co-culture model, the amount of PTX permeated after 90 min was $0.44 \mu \mathrm{g}$ and at the end of the test only $0.49 \mu \mathrm{g}$ permeated the monolayer.

It has been reported that the co-culture Caco-2/HT29-MTX model present lower values of TEER in comparison to the Caco2 monoculture, due to looser junctions between the cells, what can means the presence of more intercellular space [49]. This could lead to a higher drug permeability at the co-culture model. However, it was not observed a significant improvement of PTX permeability kinetics in the co-culture model, due to the strong interaction of

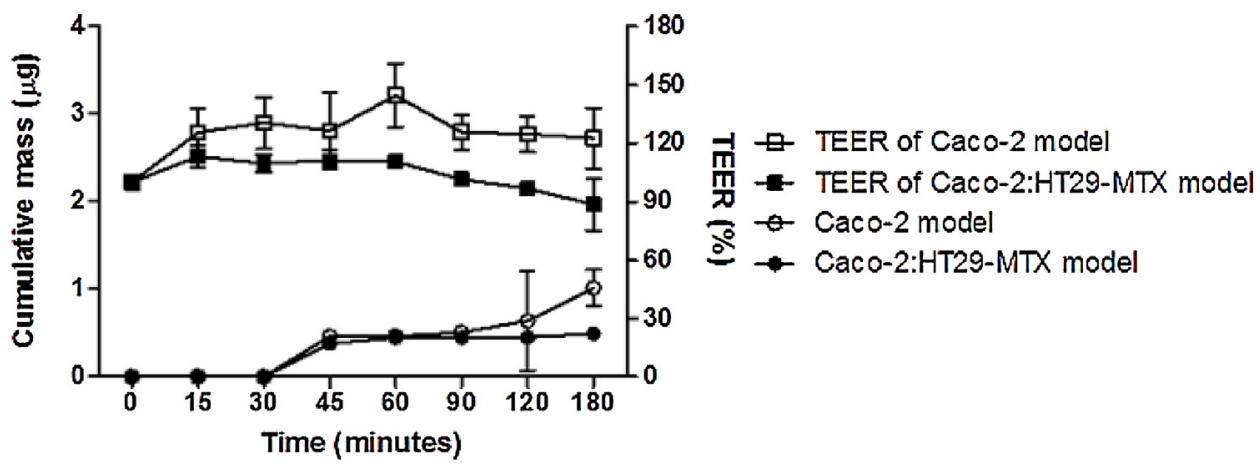

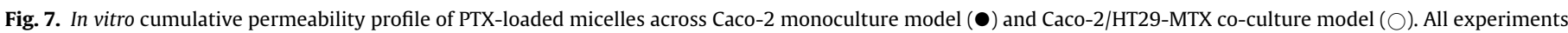
were conducted from the apical to basolateral compartment in HBSS at $37^{\circ} \mathrm{C}$. Error bars represent mean $\pm \operatorname{SD}(n=3)$. 
DMCh micelles with mucus. As the micelles are composed mainly of chitosan, a mucoadhesive polymer, the interaction between the micelles and the mucus layer secreted by HT29-MTX cell line, prevented the passage of PTX across the cell monolayer. In other words, the mucoadhesiveness of the micelles and the presence of mucus altered PTX permeability.

Comparing the permeability of PTX, it was found to be 2fold increased when loaded into DMCh compared to free drug (data not shown), which is in line with other findings. Mo et al. obtained Papp of encapsulated PTX into chitosan micelles close to $8.55 \pm 0.90 \times 10^{-6} \mathrm{~cm} / \mathrm{s}$, approximately 2 -fold improved in comparison with free PTX [48].

Regarding the TEER measurements, these values reflects the integrity of the monolayer and, a decrease on TEER values determine the opening of the cell tight junctions. As can be seen in Fig. 7, for both models no significant changes of TEER values were observed during the permeability tests, which is in agreement with the permeability results.

Based on the PTX permeability, it is suggested that these chitosan-based micelles present important mucoadhesive properties that may improve the interaction of PTX with cells, placing the anti-cancer drug in deeper contact with cancer cells, which may be more effective for the anti-tumoral activity.

\section{Conclusion}

The amphiphilic derivative 3,6-0,0'-dimyristoyl chitosan was successully synthesized by acylation of chitosan with mirystoyl chloride, as confirmed by FTIR and ${ }^{1} \mathrm{H}$ NMR spectroscopy. Both samples, namely DMCh07 (DS=6.8\%) and DMCh12 DS=12.0\%), presented self-association behavior and allowed the efficient encapsulation of paclitaxel (PTX) into micelles which displayed nano-size dimensions $(287.0-492.5 \mathrm{~nm})$ and presented high positive zeta potential $(>30 \mathrm{mV})$. The cytotoxicity assay of DMCh07 and PTX-loaded DMCh07 micelles showed that the micellar system was not toxic toward Caco-2 and HT29-MTX colorectal cancer cells in the tested concentration range as both cell lines exhibited high viability as compared to free PTX. The permeability results reflect DMCh micelles as an opportunity for oral delivery of poorly water soluble drugs due to their deeper contact with cancer cells. These results suggest the DMCh07 as a potential candidate for drug carrier of PTX or other hydrophobic drugs. However, further studies should be carried out aiming to improve the mucoadhesiveness as well as the mucopenetration of the micelles loaded with paclitaxel. In this sense, an interesting approach is the introduction of permanent positive charges on the chains of $0, O^{\prime}$-dimysristoyl chitosan as it is well known that the positive superficial charge of the micelles strongly affects its mucoadhesiveness. Additionally, knowing that mucopenetration strongly depends on the average size of the micelles, further studies should aim smaller particles $(<100 \mathrm{~nm})$ by using different strategies to produce nanocarriers.

\section{Acknowledgements}

This work was financed by FEDER - Fundo Europeu de Desenvolvimento Regional funds through the COMPETE 2020-Operacional Programme for Competitiveness and Internationalisation (POCI), Portugal 2020, and by Portuguese funds through FCT - Fundação para a Ciência e a Tecnologia/Ministério da Ciência, Tecnologia e Inovação in the framework of the project "Institute for Research and Innovation in Health Sciences" (POCI-01-0145-FEDER-007274). This research was also partially supported by CESPU/IINFACTS under the project NanoGumCESPU-2014. The authors are also grateful to CAPES, CNPq, FAPESP, IQSC/USP for financial support.

\section{References}

[1] Y. Gao, J. Xie, H. Chen, S. Gu, R. Zhao, J. Shao, L. Jia, Nanotechnology-based intelligent drug design for cancer metastasis treatment, Biotechnol. Adv. 32 (2014) 761-777.

[2] M. Borner, W. Scheithauer, C. Twelves, J. Maroun, H. Wilke, Answering patients' needs: oral alternatives to intravenous therapy, Oncologist 6 (Suppl. 4) (2001) 12-16.

[3] V.J. O'Neill, C.J. Twelves, Oral cancer treatment: developments in chemotherapy and beyond, Br. J. Cancer 87 (2002) 933-937.

[4] T.R. Halfdanarson, A. Jatoi, Oral cancer chemotherapy: the critical interplay between patient education and patient safety, Curr. Oncol. Rep. 12 (2010) 247-252.

[5] B. Mishra, B.B. Patel, S. Tiwari, Colloidal nanocarriers: a review on formulation technology, types and applications toward targeted drug delivery, Nanomedicine 6 (2010) 9-24.

[6] S.a. Agnihotri, N.N. Mallikarjuna, T.M. Aminabhavi, Recent advances on chitosan-based micro- and nanoparticles in drug delivery, J. Control. Release 100 (2004) 5-28.

[7] L. Martin, C.G. Wilson, F. Koosha, L. Tetley, A.I. Gray, S. Senel, I.F. Uchegbu, The release of model macromolecules may be controlled by the hydrophobicity of palmitoyl glycol chitosan hydrogels, J. Control. Release 80 (2002) 87-100.

[8] Z. Zhang, S. Feng, Nanoparticles of poly (lactide)/vitamin E TPGS copolymer for cancer chemotherapy: synthesis, formulation, characterization and in vitro drug release, Biomaterials 27 (2006) 262-270.

[9] A.K. Singla, A. Garg, D. Aggarwal, Paclitaxel and its formulations, Int. J. Pharm. 235 (2002) 179-192.

[10] R. Panchagnula, Pharmaceutical aspects of paclitaxel, Int. J. Pharm. 172 (1998) $1-15$.

[11] W.W.T.B. Huinink, J.M.M. Terwogt, J.H. Beijnen, B. Nuijent, A. Van Leeuwenhoek, Alternative formulations of paclitaxel, Cancer Treat. Rev. 23 (1997) 87-95.

[12] J. You, F.-Q. Hu, Y.-Z. Du, H. Yuan, B.-F. Ye, High cytotoxicity and resistant-cell reversal of novel paclitaxel loaded micelles by enhancing the molecular-target delivery of the drug, Nanotechnology 18 (2007) 495101.

[13] Z. Yao, C. Zhang, Q. Ping, L. (Lucy) Yu, A series of novel chitosan derivatives: synthesis, characterization and micellar solubilization of paclitaxel, Carbohydr. Polym. 68 (2007) 781-792.

[14] C. Zhang, P. Qineng, H. Zhang, Self-assembly and characterization of paclitaxel-loaded N-octyl-O-sulfate chitosan micellar system, Colloids Surf. B Biointerfaces 39 (2004) 69-75.

[15] N. Nishiyama, K. Kataoka, Current state achievements, and future prospects of polymeric micelles as nanocarriers for drug and gene delivery, Pharmacol. Ther. 112 (2006) 630-648.

[16] Y. Matsumura, K. Kataoka, Preclinical and clinical studies of anticancer agent-incorporating polymer micelles, Cancer Sci. 100 (2009) 572-579.

[17] T. Woraphatphadung, W. Sajomsang, P. Gonil, A. Treetong, P. Akkaramongkolporn, T. Ngawhirunpat, P. Opanasopit, pH-responsive polymeric micelles based on amphiphilic chitosan derivatives: effect of hydrophobic cores on oral meloxicam delivery, Int. J. Pharm. 497 (2016) $150-160$.

[18] C. Zhang, Q. Ping, H. Zhang, J. Shen, Preparation of N-alkyl-O-sulfate chitosan derivatives and micellar solubilization of taxol, Carbohydr. Polym. 54 (2003) $137-141$.

[19] G.-B.B. Jiang, D. Quan, K. Liao, H. Wang, Novel polymer micelles prepared from chitosan grafted hydrophobic palmitoyl groups for drug delivery, Mol. Pharm. 3 (2006) 152-160.

[20] G.S. Kwon, M. Naito, M. Yokoyama, T. Okano, Y. Sakurai, K. Kataoka, Physical entrapment of adriamycin in AB block copolymer micelles: pharm, Res. An Off. J. Am. Assoc. Pharm. Sci. 12 (1995) 192-195.

[21] D. Chang, J. Lei, H. Cui, N. Lu, Y. Sun, X. Zhang, C. Gao, H. Zheng, Y. Yin, Disulfide cross-linked nanospheres from sodium alginate derivative for inflammatory bowel disease: preparation, characterization, and in vitro drug release behavior, Carbohydr. Polym. 88 (2012) 663-669.

[22] G.-B. Jiang, D. Quan, K. Liao, H. Wang, Preparation of polymeric micelles based on chitosan bearing a small amount of highly hydrophobic groups, Carbohydr. Polym. 66 (2006) 514-520.

[23] A.B. Ebrahim Attia, Z.Y. Ong, J.L. Hedrick, P.P. Lee, P.L.R. Ee, P.T. Hammond, Y.-Y. Yang, Mixed micelles self-assembled from block copolymers for drug delivery, Curr. Opin. Colloid Interface Sci. 16 (2011) 182-194.

[24] J.a.D.M. Delezuk, M.B. Cardoso, A. Domard, S.P. Campana-Filho, Ultrasound-assisted deacetylation of beta-chitin: influence of processing parameters, Polym. Int. 60 (2011) 903-909.

[25] D.S. Silva, J.A.M. Delezuk, F.A. La Porta, E. Longo, S.P. Campana-Filho, Comparison of experimental and theoretical data on the structural and electronic characterization of chitin and chitosan, Curr. Phys. Chem. 5 (2015) $1-8$.

[26] T.D.A. Senra, D.M. Santos, J. Desbrières, S.P. Campana-Filho, Extensive N -methylation of chitosan: evaluating the effects of the reaction conditions by using response surface methodology: extensive $\mathrm{N}$-methylation of chitosan, Polym. Int. 64 (2015) 1617-1626.

[27] K. Kurita, Controlled functionalization of the polysaccharide chitin, Prog. Polym. Sci. 26 (2001) 1921-1971

[28] A. Hirai, H. Odani, A. Nakajima, Determination of degree of deacetylation of chitosan by 1H NMR spectroscopy, Polym. Bull. 94 (1991) 87-94. 
[29] A. Fiamingo, J.A.D.M. Delezuk, S. Trombotto, L. David, S.P. Campana-Filho, Extensively deacetylated high molecular weight chitosan from the multistep ultrasound-assisted deacetylation of beta-chitin, Ultrason. Sonochem. 32 (2016) 79-85.

[30] J. Lv, Q. Zhou, G. Liu, D. Gao, C. Wang, Preparation and properties of polyester fabrics grafted with O-carboxymethyl chitosan, Carbohydr. Polym. 113 (2014) 344-352.

[31] C. Chen, S. Tao, X. Qiu, X. Ren, S. Hu, Long-alkane-chain modified N-phthaloyl chitosan membranes with controlled permeability, Carbohydr. Polym. 91 (2013) 269-276.

[32] A.M.K, S.S. Shah, Determination of critical micelle ( $\mathrm{cmc}$ ) of sodium dedecyl sulfate (SDs) and effect of low concentration of pyrene on its Cmc using ORIGIN software, J. Chem. Soc. Pak. 30 (2008) 186-191.

[33] D. Sgorla, A. Almeida, C. Azevedo, É. Jose, B. Sarmento, O. Albuquerque, Development and characterization of crosslinked hyaluronic acid polymeric films for use in coating processes, Int. J. Pharm. 511 (2016) 380-389.

[34] F. Antunes, F. Andrade, F. Araújo, D. Ferreira, B. Sarmento, Establishment of a triple co-culture in vitro cell models to study intestinal absorption of peptide drugs, Eur. J. Pharm. Biopharm. 83 (2013) 427-435.

[35] A. Pavinatto, A.L. Souza, J.aA. Delezuk, F.J. Pavinatto, S.P. Campana-Filho, O.N Oliveira, Interaction of $\mathrm{O}$-acylated chitosans with biomembrane models: probing the effects from hydrophobic interactions and hydrogen bonding, Colloids Surf. B Biointerfaces 114 (2014) 53-59.

[36] C.Y. Choi, S.B. Kim, P.K. Pak, D.I. Yoo, Y.S. Chung, Effect of N-acylation on structure and properties of chitosan fibers, Carbohydr. Polym. 68 (2007) $122-127$.

[37] Y. Tong, S. Wang, J. Xu, B. Chua, C. He, Synthesis of O,O'-dipalmitoyl chitosan and its amphiphilic properties and capability of cholesterol absorption, Carbohydr. Polym. 60 (2005) 229-233.

[38] D.M. dos Santos, A. de L. Bukzem, S.P. Campana-Filho, Response surface methodology applied to the study of the microwave-assisted synthesis of quaternized chitosan, Carbohydr. Polym. 138 (2016) 317-326.

[39] S. Hirano, Y. Yamaguchi, M. Kamiya, Novel N-saturated-fatty-acyl derivatives of chitosan soluble in water and in aqueous acid and alkaline solutions, Carbohydr. Polym. 48 (2002) 203-207.
[40] Y. Hu, Y. Du, J. Yang, Y. Tang, J. Li, X. Wang, Self-aggregation and antibacterial activity of N-acylated chitosan, Polymer (Guildf) 48 (2007) 3098-3106.

[41] M.E.I. Badawy, E.I. Rabea, T.M. Rogge, C.V. Stevens, G. Smagghe, W. Steurbaut, M. Ho, Synthesis and fungicidal activity of new N, O-acyl chitosan derivatives, Biomacromolecules (2004) 589-595.

[42] M.E.I. Badawy, E.I. Rabea, T.M. Rogge, C.V. Stevens, W. Steurbaut, M. Höfte, G. Smagghe, Fungicidal and insecticidal activity of O-acyl chitosan derivatives, Polym. Bull. 54 (2005) 279-289.

[43] J.P. Guthrie, Hydrolysis of esters of oxy acids: pKa values for strong acids; Brønsted relationship for attack of water at methyl; free energies of hydrolysis of esters of oxy acids; and a linear relationship between free energy of hydrolysis and pKa holding over a ran, Can. J. Chem. 56 (1979) 2342-2354.

[44] A. Domard, A perspective on 30 years research on chitin and chitosan, Carbohydr. Polym. 84 (2011) 696-703, http://dx.doi.org/10.1016/j.carbpol. 2010.04.083.

[45] M. Huo, Y. Zhang, J. Zhou, A. Zou, J. Li, Formation microstructure, biodistribution and absence of toxicity of polymeric micelles formed by N-octyl-N,O-carboxymethyl chitosan, Carbohydr. Polym. 83 (2011) 1959-1969.

[46] K.Y. Lee, W.H. Jo, I.C. Kwon, Y.-H. Kim, S.Y. Jeong, Physicochemical characteristics of self-aggregates of hydrophobically modified chitosans, Langmuir 14 (1998) 2329-2332.

[47] R.D. Dabholkar, R.M. Sawant, D.A. Mongayt, P.V. Devarajan, V.P. Torchilin, Polyethylene glycol -phosphatidylethanolamine conjugate (PEG -PE) -based mixed micelles: some properties, loading with paclitaxel, and modulation of P-glycoprotein-mediated efflux, Int. J. Pharm. 315 (2006) 148-157.

[48] R. Mo, X. Jin, N. Li, C. Ju, M. Sun, C. Zhang, Q. Ping, The mechanism of enhancement on oral absorption of paclitaxel by N-octyl-O-sulfate chitosan micelles, Biomaterials 32 (2011) 4609-4620.

[49] F. Araújo, B. Sarmento, Towards the characterization of an in vitro triple co-culture intestine cell model for permeability studies, Int. J. Pharm. 458 (2013) 128-134. 